\title{
Thought Problems and Aggression Over Time Among Youth in Foster Care
}

\author{
Tatjana M. Farley ${ }^{1}$ (D) $\cdot$ Lenore M. McWey $^{1} \cdot$ Thomas Ledermann $^{1}$
}

Accepted: 17 September 2021 / Published online: 29 September 2021

(c) The Author(s), under exclusive licence to Springer Science+Business Media, LLC, part of Springer Nature 2021

\begin{abstract}
Background Youth in foster care may demonstrate high levels of aggression and thought problems. There is a growing trend to consider mental health symptoms of youth involved with the foster care system from a developmental trauma perspective.

Objective The aim of this study was to test if trauma, race, age, and gender predicted variability in thought problems and aggression for youth in foster care.

Method The sample $(n=303)$ included youth in out-of-home placements with a mean age of 14 years, a diverse racial demographic, and almost an equal percentage of males and females. Participants were assessed over three waves using a series of multilevel growth curve models.

Results Results indicated significant decreases in thought problems and aggression and youth with higher levels of trauma reported higher initial levels and swifter decreases of both thought problems and aggression over time.

Conclusions While trauma was associated with aggression and thought problems, results found that youth demonstrated significant decreases in aggression and thought problems over time. A better understanding of the long-term effects of trauma on thought problems and aggression of youth in foster care is needed. While our findings suggest foster care may be protective in fostering resilience, additional research on the nature of potential positive effects of foster care on aggression and thought problems is suggested.
\end{abstract}

Keywords Children · Foster Care - Aggression · Thought Problems, Growth Curve Modeling

This document includes data from the National Survey on Child and Adolescent Well-Being, which was developed under contract with the Administration on Children, Youth, and Families, U.S. Department of Health and Human Services (ACYF/DHHS). The data have been provided by the National Data Archive on Child Abuse and Neglect. The information and opinions expressed herein reflect solely the position of the authors. Nothing herein should be construed to indicate the support or endorsement of its content by ACYF/DHHS.

Tatjana M. Farley

tmf18m@my.fsu.edu

1 Florida State University, Tallahassee, FL, United States 


\section{Thought Problems and Aggression Over Time Among Youth in Foster Care}

Youth in foster care are generally at risk for developing aggressive behavior problems (De Robertis and Litrownik 2004; Heflinger et al. 2000), but youth with aggression problems are significantly more likely to experience unfavorable foster care placement terminations (De Robertis and Litrownik 2004; Strijker et al. 2005). Moreover, heightened aggression is associated with future criminal behavior (Ambrose and Mayne 1999; Glancy and Saini 2005; Little et al. 2003; Mooney and Daffern 2011), and youth involved with the foster care system are more likely to be involved in the juvenile justice system, with dual system involvement rates ranging between 44 and 70\% (Herz and Dierkhising 2019; Korbin et al. 2015). Previous research has proposed that one's thoughts may play an important role in aggression (Fives et al. 2011, Smeijers et al. 2018). Current treatment outcomes tend to be poor for youth exhibiting high levels of aggression (Cantos and Gries 2010; Fives et al. 2011); therefore, more research is needed to better understand what prompts aggressive behavior. To explore this gap, the aims of this study were to test distinct trajectories of thought problems and aggression for youth in foster care and determine the extent to which trauma, race, age, and sex predicted initial levels and changes.

\section{Aggression and Thought Problems}

Aggression, which is often defined as hostile, destructive, or injurious behavior, has the potential to cause serious harm to others (Hamama and Arazi 2012; Ho et al. 2010; Tonnaer et al. 2019). Youth in foster care tend to have higher levels of behavior problems, including aggression, compared to their peers in the general community (Keller et al. 2001; Perry and Price 2017; Tarren-Sweeney 2008). One study focused on determining the clinical status of children in state custody found that $34 \%$ of youth were rated as having significant behavior problems, with the greatest numbers meeting the clinical range for aggressive, delinquent, and withdrawn behaviors (Heflinger et al. 2000). Aggressive behaviors may result in youths' social challenges and inform long-term consequences, such as psychopathology and incarceration (Henggeler and Sheidow 2003; Perry and Price 2017).

Thought problems are conceptualized as consistent, repetitive, and negative thought processes about self, others, or situations. For the purposes of this study, the conceptualization was rooted in the Youth Self Report (YSR; Achenbach 1991) assessment, in which respondents answer questions such as "I can't get my mind off certain things" or "I do things other people think are strange." Research suggests that youth in foster care are at risk for developing thought problems (Clausen et al. 1998; Marinkovic and Backovic 2007), with nearly $60 \%$ struggling with thought problems at the clinical level (Clausen et al. 1998). A qualitative study of 17 adolescents in foster care suggested that thought problems may be shaped by their sense of being devalued by others and their internalization of those negative views (Kools 1997).

Thought problems, including irrational beliefs, affect how individuals interpret situations and events which can result in aggression (Fives et al. 2011; Hamama and Arazi 2012). For instance, one study found that youths' irrational beliefs (e.g., thoughts of worthlessness or injustice) significantly predicted their self-reported levels of aggression (Fives et al. 2011). Additionally, there is some empirical support suggesting social cognitions, such as a 
negative view of self and others, are associated with how social information is processed, resulting in increased aggression (Bradshaw et al. 2013). The combination of aggression and thought problems was among the most elevated comorbidity groups predicting psychopathology in a sample of adolescents in low-income, urban youth (Tolan and Henry 1996). Specifically, those with high levels of thought problems and with aggression had poorer prognoses than those with high levels of aggression alone (Tolan and Henry 1996). Importantly, there may be differences in how youth express symptoms over time (Weems et al. in press). For instance, among a sample of 202 youth whose neighborhoods experienced considerable damage from Hurricane Katrina, researchers found both continuity and change in post-traumatic stress symptoms over time with some symptoms more stable in younger compared to older youth (Weems et al. in press). Taken together, it is important to better understand the trajectories of thought problems and aggression for youth in foster care as this can inform clinical treatment.

\section{Theoretical Background}

The developmental trauma perspective contributes to an understanding of the association between thoughts problems and aggression of youth in foster care. The framework was designed to better capture the spectrum of symptoms of youth who have been exposed to interpersonal violence and disruptions in their caregiving (Van der Kolk et al. 2009). This perspective can be used to highlight how unsafe parent-child relationships may result in thought problems and aggressive behaviors. Exposure to trauma, especially when inflicted by caregivers, can have pervasive effects on child development (Van der Kolk 2005). Children's experiences of trauma can affect the brain, including neurobiological development, which influences their capacity to integrate emotional, sensory, and cognitive information into a cohesive whole (Van der Kolk 2005). Indeed, youth who experience trauma often struggle with the ability to regulate their affective, behavioral, and relational experiences (Kisiel et al. 2014). Thus, the complex trauma experienced by youth in foster care may result in problematic thoughts and behaviors because of difficulties in neurobiological development, specifically misperceptions of cues and contexts.

Direct links between parental rejection, thought problems, and aggressive behaviors have been found using retrospective reports from a clinical sample of 123 adult male forensic psychiatric outpatients (Smeijers et al. 2018). Incarcerated youth were also found to have higher levels of cognitive distortions causing externalizing behaviors when compared with youth in schools (Barriga et al. 2000). Cognitive distortions have been found to mediate the relationship between attachment and aggressive behaviors (de Vries et al. 2016), exhibiting the impact on the individual and their relationships. Although previous studies were not specific to the foster care context, they point to the importance of thought problems in our understanding of aggressive behaviors among at-risk populations.

\section{The Present Study}

There is a growing trend to consider mental health symptoms of youth, particularly those involved with the foster care system, from a developmental trauma perspective (van der Kolk 2005). Youth in foster care tend to demonstrate high levels of aggression (De Robertis and Litrownik 2004; Heflinger et al. 2000) and thought problems (Clausen et al. 1998; 
Marinkovic and Backovic 2007). Moreover, research indicates that aggression and thought problems may go hand in hand (de Vries et al. 2016; Smeijers et al. 2018) as problematic aggression is a key feature distinguishing youth in foster care who do not improve with treatment (Cantos and Gries 2010). Therefore, a better understanding of mental health symptoms may be central to improving outcomes of youth in the foster care system (den Dunnen et al. 2012; Frensch and Cameron 2002). However, the known studies linking problematic parent-adolescent relationships, thought problems, and aggression are cross-sectional and are not specific to youth in foster care. This is problematic because there may be important developmental and temporal linkages in youths' expression of PTSD symptoms (Weems et al. in press).

Given the gaps in the current research, the primary aim of this study was to test the distinct longitudinal trajectories of thought problems and aggression for youths in foster care. Because past research has demonstrated that youths' mental health symptoms tend to decline over their stay in foster care (McWey et al. 2010), it was hypothesized that levels of both thought problems and aggression would decrease over time. In accordance with the developmental trauma framework, it was also hypothesized that higher levels of trauma would be related to higher levels of both thought problems and aggressive behaviors. Additionally, key sociodemographic characteristics may be related to the mental health trajectories of youth in foster care (McWey et al. 2010). Because there is a persistent overrepresentation of youth of color in the U.S. foster care (U.S. Department of Health and Human Services 2015) and juvenile justice systems (Sevin Goldstein et al. 2007; Henning 2012), race and ethnicity were tested as predictors. Moreover, because age and gender also may be linked with thought problems and aggression (Coie and Dodge 1998; Fives et al. 2011; Kanne and Mazurek 2010; Valois et al. 2002), they were tested as predictors of the levels and trajectories of thought problems and aggression.

\section{Method}

\section{Sample and Procedures}

The data used for this study were derived from the National Survey of Child and Adolescent Well-Being (NSCAW II) with approval from the investigators' University Institutional Review Board (IRB\# 2018.26592). The authors declare no conflicts of interest. NSCAW II is a nationally representative longitudinal survey of children and families who were under child welfare system investigations during 2008-2009; in some families the children were removed from the home and placed in out-of-home care $(n=727)$ and the other families remained intact $(n=5,501)$. To achieve U.S. national representation, NSCAW II researchers implemented a two-stage stratified sampling design. First, they divided the U.S. into sampling units, then systematically sampled from each unit so that each represented a distinct U.S. region. Next, a representative number of children was selected from each unit (Dowd et al. 2010). Youth were surveyed across three waves of data collection (Wave 1 baseline, Wave 2 taken 18 months later, and Wave 3 taken 36 months after baseline). Data include information provided by youth, caregivers, caseworkers, teachers, as well as administrative record data. NSCAW II examines child and family well-being outcomes related to child welfare system involvement (Dowd et al. 2010). For more details about the NSCAW II data, 
including information about sampling, informed consent, and item response rates, please refer to the National Data Archive on Child Abuse and Neglect.

The focus of this study was specifically on adolescents in out-of-home care; therefore, the sample was restricted to those who were removed from the home. Only adolescents ages 11 years and older completed the measures of interest for this study $(n=303)$, therefore the analytic sample included adolescents ranging in ages between 11 years and 17 years with a mean age of 14 years $(S D=1.8)$. The racial and ethnic demographic characteristics of the adolescents included: $35.3 \%$ Black, $28.1 \%$ White, $24.4 \%$ Hispanic, $12.2 \%$ other including adolescents who identify as American Indian, Asian/Hawaiian/Pacific Islander, or unknown or preferred not to answer. The subsample included a near equal number of male (48\%) and female (52\%) participants. Out-of-home placements consisted of $44 \%$ in traditional foster care placements, $34 \%$ in kinship care, $20 \%$ in group homes or residential care, and $2 \%$ in "other" out-of-home child protective placements.

\section{Measures}

Youth Self-Report The YSR is the youth-report version of the Child Behavior Checklist (Achenbach and Rescorla 2001) and it was administered to adolescents ages 11 and older. The YSR has 112 items and specific subscales designed to assess self-reported feelings and behaviors (Achenbach 1991). From the YSR, the aggressive behavior (Cronbach's $\alpha=0.98$ ) and thought problems (Cronbach's $\alpha=0.62$ ) subscales were used. The aggressive behavior subscale includes items such as "I argue a lot" and "I destroy things that belong to others." Thought problems was comprised of items assessing things such as "I can't get my mind off certain thoughts." Response options range from $0=$ not true, $1=$ somewhat or sometimes true, 2 = very true or often true with higher scores indicating higher levels of symptoms.

Trauma Youth also completed The Trauma Symptom Checklist for Children (TSCC; Briere 1996). This measure provides an index of current post-traumatic stress (PTS) symptomology based on youth self-report. Youth indicated how often they experienced a thought, feeling, or behavior using a 4-point scale $(0=$ never, $1=$ sometimes, $2=$ lots of times, $3=$ almost all the time). Examples of symptoms include "bad dreams or nightmares" or "going away in my mind, trying not to think." The measure consists of 54 items and was standardized on a large sample of racially and economically diverse children (Kolko et al. 2010). For the present study, the Cronbach's alpha was $\alpha=0.98$.

Demographic characteristics Demographic characteristics tested in preliminary analyses included sex, age (in years), race (Black, White, and other including: American Indian, Asian/Hawaiian/Pacific Islander) and ethnicity (Hispanic, Non-Hispanic).

\section{Analytical Plan}

The first author takes full responsibility for the integrity of the data and the accuracy of the data analyses. The analyses were conducted using IBM SPSS using multilevel modeling. Multilevel Modeling was chosen over Structural Equation Modeling because the former is more robust when there are missing data and when the sample size is small (Ledermann and 
Kenny 2017). A series of multilevel growth curve models were estimated to test the aims of the study. First, an unconditional intercept-only model was run for both thought problems and aggression. This model served as a baseline. Next, a growth curve model was run that included time as a predictor (coded 0,1 , and 2 for each wave of data). Race, sex, and trauma were added stepwise as predictors to each model. So, the third model had time and race as simple effects, followed by a model with interaction terms for race and time. The fourth model included sex and time with simple effects, followed by a model with an interaction term for sex and time. The next model had time, sex, and trauma as simple effects. The final model included time, sex, trauma, and the interaction term between trauma and time. The model with the lowest Akaike Information Criteria (AIC) and Bayesian Information Criteria (BIC) was selected as the final model. Trauma at baseline was mean-centered.

Table 1 Means and standard deviations

\begin{tabular}{lllllllll}
\hline & Females & & & & Males \\
\hline Variable & Black & Hispanic & White & Other & Black & Hispanic & White & Other \\
Trauma & 10.15 & 10.65 & 10.33 & 10.68 & $7.11(5.36)$ & 7.91 & 6.39 & 8.50 \\
& $(5.43)$ & $(6.73)$ & $(5.63)$ & $(5.43)$ & & $(5.86)$ & $(4.75)$ & $(6.79)$ \\
Thought problems 1 & $4.62(3.37)$ & 4.44 & 4.11 & 4.04 & $2.81(2.50)$ & 3.21 & 3.46 & 4.43 \\
& & $(3.73)$ & $(3.01)$ & $(3.23)$ & & $(2.99)$ & $(2.57)$ & $(3.86)$ \\
Thought problems 2 & $4.22(2.67)$ & 3.40 & 3.14 & 3.89 & $2.68(2.67)$ & 3.00 & 3.22 & 3.50 \\
& & $(2.74)$ & $(2.85)$ & $(3.64)$ & & $(2.71)$ & $(2.56)$ & $(3.44)$ \\
Thought problems 3 & $3.29(3.05)$ & 3.18 & 4.54 & 3.50 & $2.72(2.09)$ & 2.40 & 2.88 & 2.25 \\
& & $(2.63)$ & $(3.57)$ & $(2.32)$ & & $(2.85)$ & $(2.42)$ & $(2.22)$ \\
Aggressive Behavior & 10.92 & 10.23 & 9.96 & 10.09 & $7.84(5.84)$ & 8.58 & 9.26 & 7.79 \\
1 & $(7.32)$ & $(8.48)$ & $(6.83)$ & $(6.54)$ & & $(6.09)$ & $(5.34)$ & $(6.74)$ \\
Aggressive Behavior & 10.38 & 9.93 & 9.81 & 9.44 & $6.68(4.41)$ & 9.39 & 8.59 & 10.10 \\
2 & $(6.39)$ & $(7.22)$ & $(5.88)$ & $(6.11)$ & & $(6.18)$ & $(5.27)$ & $(7.09)$ \\
Aggressive Behavior & 10.29 & 7.82 & 12.54 & 10.17 & $6.52(5.49)$ & 6.33 & 7.29 & 6.00 \\
3 & $(9.10)$ & $(5.04)$ & $(7.37)$ & $(4.73)$ & & $(4.78)$ & $(5.32)$ & $(4.16)$ \\
\hline
\end{tabular}

Standard deviations are given in parenthesis

Table 2 Correlations, means, and standard deviations of the study variables

\begin{tabular}{llllllll}
\hline Variable & 1 & 2 & 3 & 4 & 5 & 6 & 7 \\
\hline 1. Trauma & - & & & & & & \\
2. Thought Problems W1 & $0.566^{* *}$ & - & & & & & \\
3. Aggression W1 & $0.436^{* *}$ & $0.659^{* *}$ & - & & & & \\
4. Thought Problems W2 & $0.437^{* *}$ & $0.567^{* *}$ & $0.401^{* *}$ & - & & & \\
5. Aggression W2 & $0.334^{* *}$ & $0.397^{* *}$ & $0.631^{* *}$ & $0.520^{* *}$ & - & & \\
6. Thought Problems W3 & $0.277^{* *}$ & $0.479^{* *}$ & $0.309^{* *}$ & $0.530^{* *}$ & $0.318^{* *}$ & - & \\
7. Aggression W3 & $0.175^{*}$ & $0.401^{* *}$ & $0.569^{* *}$ & $0.345^{* *}$ & $0.598^{* *}$ & $0.530^{* *}$ & - \\
$M$ & 8.90 & 3.81 & 9.40 & 3.34 & 9.14 & 3.10 & 8.27 \\
$S D$ & 5.92 & 3.12 & 6.71 & 2.83 & 6.01 & 2.65 & 6.19 \\
$n$ & 298 & 300 & 300 & 223 & 223 & 117 & 117 \\
\hline
\end{tabular}

$* p<0.05 . * * p<0.01$. (2-tailed) 


\section{Results}

Table 1 shows descriptive statistics for the study variables by sex, race, and ethnicity. Scores for all study variables were higher for females compared to males across race and ethnicity. Table 2 displays the correlations between study variables as well as their means and standard deviations. Trauma, thought problems, and aggression were all significantly correlated with one another.

\section{Thought Problems}

Table 3 shows the fit indices of the models for thought problems and aggressive behavior. The AIC and BIC of the model for thought problems with time as a predictor were lower than those of the intercept-only model (see Table 3), which indicates that the model with time was the better model. The initial status (intercept) and linear growth rate were 3.78 $(S E=0.18, p<0.01)$ and $-0.48(S E=0.11, p<0.01)$, respectively. This suggested that the average of thought problems was 3.78 at the first wave and they decreased an average of 0.48 each wave. The variance of both the intercept and linear slope were significant, indicating that the initial status and linear change varied across adolescents. The covariance ( $b=-1.19, S E=0.43, p<0.01)$ between the intercept and the linear growth parameter was negative and significant. This suggests that adolescents with higher thought problem scores at baseline had a faster linear decrease compared with adolescents with lower scores who had slower decreasing rates.

Adding race as a predictor worsened the fit of the model, whereas the inclusion of sex led to an improvement of the model. The model with sex and time was better than the model with time only. In this model, sex was a positive predictor of thought problems $(b=0.82$,

Table 3 Model fit information for thought problem and aggressive behavior

\begin{tabular}{lll}
\hline Model & AIC & BIC \\
\hline Thought problems & & $3,105.2$ \\
Intercept-only model & $3,091.8$ & $3,096.1$ \\
Growth curve model w/time & $3,069.3$ & $3,113.9$ \\
Growth curve model w/race & $3,073.8$ & $3,132.4$ \\
Growth curve model w/race*time & $3,078.8$ & $3,094.8$ \\
Growth curve model w/sex & $3,063.6$ & $3,099.8$ \\
Growth curve model sex*time & $3,064.1$ & $2,977.5$ \\
Growth curve w/sex \& trauma & $2,941.9$ & $2,959.3$ \\
Growth curve w/sex, trauma \& trauma*time & $2,919.2$ & $4,034.6$ \\
Aggressive behavior & & $4,041.4$ \\
Intercept-only model & $4,021.3$ & $4,059.9$ \\
Growth curve model w/time & $4,014.6$ & $4,078.2$ \\
Growth curve model w/race & $4,019.7$ & $4,040.4$ \\
Growth curve model w/race*time & $4,024.7$ & $4,046.8$ \\
Growth curve model w/sex & $4,009.2$ & $3,944.9$ \\
Growth curve model sex*time & $4,011.2$ & $3,931.0$ \\
Growth curve w/sex \& trauma & $3,909.3$ & $3,891.0$ \\
Growth curve w/sex, trauma \& trauma*time & &
\end{tabular}

$A I C=$ Akaike Information Criterion, $B I C=$ Bayesian Information Criterion 
$S E=0.29, p<0.01$, revealing that the initial level of thought problems for females was significantly higher than for males.

Building on this growth curve model with sex, AIC and BIC suggest that the model with predictors of time, sex, trauma and the interaction of trauma and time was the best fitting. In this final model, trauma and the trauma by time interaction were significant (see Table 4). Figure 1 shows this interaction between trauma and time on thought problems for low and high trauma defined as minus one $S D$ and plus one $S D$, respectively. Adolescents with higher levels of trauma had subsequent high levels of thought problems, which decreased after 36 months to a similar range of adolescents with low trauma. In contrast, adolescents with low trauma had subsequent low thought problems which remained stable over study participation.

\section{Aggression}

The AIC of the model for aggression with time as a predictor was lower than the AIC of the intercept-only model, whereas the BIC was slightly higher (see Table 3). In the more complex model with time as predictor, the initial level and linear growth rate for aggression were $9.44(S E=0.38, p<0.01)$ and $-0.60(S E=0.23, p<0.05)$, respectively. This suggested that the average aggression was 9.44 at baseline and decreased an average of 0.60 each year. The variances in both the intercept and linear slope were significant, indicating that the initial

Table 4 Results of the final multilevel models predicting thought problems and aggressive behavior

\begin{tabular}{lllllll}
\hline & \multicolumn{3}{l}{ Thought Problems } & \multicolumn{4}{l}{ Aggression } \\
\hline Predictor & $b$ & $S E$ & $95 \%$ CI & $b$ & $S E$ & $95 \%$ CI \\
\hline Intercept & $1.01 *$ & 0.43 & {$[0.17,1.85]$} & $4.41 * *$ & 1.04 & {$[2.37,6.45]$} \\
Time & 0.35 & 0.02 & {$[0.31,0.39]$} & $0.93 *$ & 0.40 & {$[0.15,1.71]$} \\
Sex & 0.11 & 0.26 & {$[-0.40,0.62]$} & 0.58 & 0.64 & {$[-0.67,1.83]$} \\
Trauma & $0.30^{* *}$ & 0.03 & {$[0.24,0.36]$} & $0.48 * *$ & 0.06 & {$[0.36,0.60]$} \\
Trauma-time interaction & $-0.10^{* *}$ & 0.02 & {$[-0.14,-0.06]$} & $-0.18^{* *}$ & 0.04 & {$[-0.26,-0.10]$} \\
\hline
\end{tabular}

$b=$ unstandardized point estimate, $S E=$ standard error, $\mathrm{CI}=$ confidence interval

Time was coded 0,1 , and 2 , sex was coded $0=$ male, $1=$ female, trauma was mean-centered. Random effects for $\mathrm{TP}=2.10$ for time $1,0.39$ for time 2 , and 0.10 for time 3 . Random effects for $\mathrm{AG}=39.1$ for time $1,6.52$ for time 2 , and 1.44 for time 3

${ }^{*} p<0.05, * * p<0.01$ (2-tailed)

Fig. 1 Interaction between time and trauma with thought problems outcome. Adolescents with high levels of trauma tended to report higher levels of thought problems that decreased to a level similar to adolescents with low trauma at 36 months. Adolescents with low trauma tended to report low thought problems, which remained stable over time




level and the linear change varied across adolescents. Moreover, the covariance between the intercept and time was negative and significant $(b=-3.83, S E=1.77, p<0.05)$, indicating adolescents with high initial aggression scores had a faster linear decline, whereas adolescents with low initial aggression scores had a slower decline.

The addition of the predictors of race and the interaction term of race and time worsened the fit of the model; however, adding sex improved the fit of the model. Results of this model showed that sex was a significant predictor of aggression $(b=1.80, S E=0.65$, $p<0.01)$, meaning the initial status was significant higher on average for females than for males.

Building on the model with sex as predictor, AIC and BIC suggest that the model with predictors of time, sex, trauma and the interaction between trauma and time was the best fitting model. Results of this final model showed that both the effect of trauma and the trauma by time interaction were significant (see Table 4). The effect of trauma on aggression was positive and the interaction was negative. These results suggest that a higher trauma score was associated with higher aggression at baseline with a significant linear decrease in aggression as trauma decreased. Figure 2 illustrates the interaction effect of trauma and time on thought problems for low (minus $1 S D$ ) and high (plus $1 S D$ ) trauma. Adolescents with higher levels of trauma had subsequent high levels of aggression, which decreased to a similar range of adolescents with low trauma. In contrast, adolescents with low trauma had subsequent low aggression which remained stable over study participation.

\section{Discussion}

The primary aim of this study was to test the linkages between trauma, thought problems and aggression over time for youth in foster care. Consistent with our hypothesis, results indicated significant decreases in thought problems and aggression over time. Additionally, youth with higher levels of trauma reported higher initial levels and swifter decreases in both thought problems and aggression compared to those with lower levels of trauma. Moreover, the initial status of both thought problems and aggression was significantly higher for females than for males; however, when trauma was included as a predictor, sex was no longer significant.

Reductions in thought problems and aggression of youth in foster care are important findings given that these youth often experience substantial transitions in their lives, including

Fig. 2 Interaction between time and trauma with aggression outcome. Adolescents with higher levels of trauma tended to be higher in aggression, and their aggression levels decreased to those similar to adolescents with low trauma over 36 months. In contrast, adolescents low in trauma reported lower aggression, which remained stable over the study period

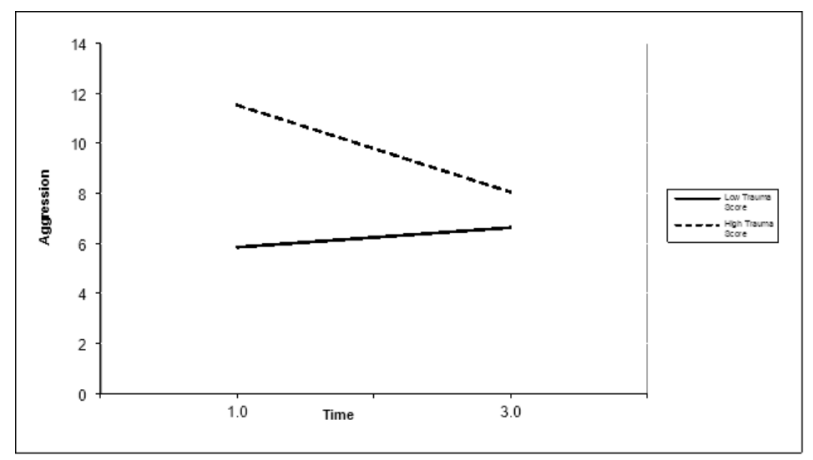


being removed from their homes due to exposure to trauma (McWey et al. 2010). Our findings are consistent with past research demonstrating lower levels of some post-traumatic stress symptoms over time for adolescents (Weems et al. in press), and extend this work by testing these paths specifically for youth in foster care. Removing youth from high riskfamily situation has positive effects on their emotional and behavioral experiences (Cicchetti and Rogosch 2002), which may reinforce the decreases in both thought problems and aggression over time. Although our findings suggest foster care may be protective in fostering resilience, additional research on the nature of potential positive effects of foster care on trajectories of aggression and thought problems is needed.

The high rates of mental health concerns among youth in foster care have been well documented (e.g., Clausen et al. 1998; De Robertis and Litrownik 2004; Heflinger et al. 2000). A connection between thought problems and aggression has been found in youth in the general population (de Vries et al. 2016); however, this connection had not yet been explored among adolescents in foster care. This is problematic because high levels of aggression are associated with poorer treatment prognoses for youth in foster care (Cantos and Gries 2010); plus, there may be key developmental and temporal linkages in PTSD symptoms (Weems et al. in press). As such, results of this study contribute to the research by demonstrating parallel declining trajectories of thought problems and aggression for foster care youth.

According to the developmental trauma perspective, youth exposed to trauma may develop maladaptive coping strategies involving cognitive distortions and aggression (van der Kolk 2005). Indeed, previous research also suggests that trauma symptoms are associated with aggression (Scott et al. 2013). A youth's expression of their responses to stress and trauma may be misunderstood and labeled as oppositional, destructive, or defiant (Knoverek et al. 2013; van der Kolk 2005). The significant associations between trauma, thought problems, and aggression found over time may be used to help to depict a youth's challenges integrating emotional, sensory, and cognitive information into a prosocial cohesive whole when coping with trauma (van der Kolk 2005). From a developmental trauma framework, youths' trauma symptoms may be better understood as efforts to regulate emotional distress and minimize perceived threat (van der Kolk 2005). Therefore, the study's findings emphasize the importance of conceptualizing the symptoms of youth exposed to trauma in such a way and using a developmental trauma framework to inform clinical treatment efforts.

Literature has indicated that, among the general population, males tend to be more aggressive and are more likely to show outward expressions of anger compared to females (Johnson et al. 2013; Tremblay et al. 2005). However, research suggests that females tend to manage emotions by internalizing their feelings (Sharp et al. 2005) and express aggression after unprocessed emotions build up (Berkowitz 2012). Interestingly, the sample used in this study had females with higher rates of aggression than males, and the females scores, on average, higher than those reported for a U.S. clinical sample of youth. (Thurber and Sheehan 2012). It is noteworthy, though, that females also reported higher levels of trauma, which may help explain why they reported being more aggressive. While males typically report more traumatic exposure, females are more likely to be exposed to toxic trauma, such as sexual abuse or interpersonal traumas perpetrated by someone close to them (Christiansen and Hansen 2015; Goldberg and Freyd 2006; Tolin and Foa 2008), which may play a role in the way females process such trauma. During adolescence, girls tend to become more self-conscious, report lower self-esteem, and are more likely to accommodate and be more compliant in their interactions (Chaplin et al. 2005; Farley et al. 2020). This could suggest 
that how girls are socialized to be more compliant, resulting in more self-consciousness and lower self-esteem, may contribute to sex differences in the subjective experiences of trauma during and after the event, and may play an important role in explaining sex differences (Spindler et al. 2010). In addition, it has been found that helplessness and negative posttraumatic cognitions about self and the world may add to the linkages between sex and severity of responses to trauma, such as post-traumatic stress disorder severity (Christiansen and Hansen 2015). This also emphasizes potential clinical implications of a developmental trauma perspective in highlighting and understanding how females may be struggling to integrate the emotional, sensory, and cognitive information of their subjective experiences into a cohesive whole (Van der Kolk 2005).

Although the initial levels of aggression were higher for females compared to males in this study, growth curve findings suggested that trauma was a more significant predictor than sex for both thought problems and aggression. Considering the developmental trauma framework, youth who experience complex trauma may have difficulties integrating emotional, sensory, and cognitive information, which may lead to maladaptive efforts to protect themselves from further harm (van der Kolk 2005). Their thoughts about perceived threats may lead to their displays of aggressive behaviors as attempts to avoid further exposure to trauma.

These findings point to important ways in which we can better target clinical approaches for adolescents struggling with thought problems and aggression. Results highlight linkages between trauma, thought problems, and aggression, bolstering the relevance of the developmental trauma perspective for youth involved with the foster care system. This perspective suggests that a focus on addressing the trauma rather than thought problems or aggression in isolation, may yield more sustainable change over time (van der Kolk 2005).

Notably, the Substance Abuse and Mental Health Services Administration (SAMHSA 2014) states that addressing trauma is an important element of effective mental health service delivery and noted six key principles of a trauma informed approach. They include: (a) safety; (b) trustworthiness and transparency; (c) peer support; (d) collaboration and mutuality; (e) empowerment, voice, and choice, and (f) cultural, historical, and sex issues (p. 10). It is important to understand people's experiences and behaviors in the context of coping strategies designed to survive adversity and overwhelming experiences, regardless of if these circumstances occurred in the past or are currently manifesting (SAMHSA 2015). Under the SAMHSA guidelines of trauma-informed care, as well as the developmental trauma framework, those who work with youth demonstrating aggressive behaviors should consider these behaviors in the context of trauma and coping. Addressing the underlying emotional distress that may be influencing the need to cope, rather than the symptoms themselves, may be critical to their healing (SAMHSA 2015).

\section{Limitations and Future Directions}

While this study relied on a nationally representative dataset of youth involved in the child welfare system, there are some limitations that warrant consideration. Although the NSCAW II dataset includes adolescents involved with the child welfare system regardless of removal from the home, this study utilized a subset of the sample which focused specifically on youth in out-of-home placements. This may limit the findings' generalizability. Regression towards the mean can also be seen as a limitation within the study. Moreover, 
results indicated significant associations between trauma, thought problems, and aggression; however, causation cannot be substantiated. The dataset includes biological sex as a variable but does not include gender identity, limiting the understanding of the results within the context of gender identity as it relates to trauma, thought problems, and aggression. The idea of heterotypic continuity may also play a role in the findings, in that aggression may be expressed differently over time and may give way to other problems (Weems et al. in press). Additionally, all the variables of interest were based on self-reported data, creating biases as differences have been found in youth's and caregiver's reports of adolescent mental health (De Los Reyes and Kazdin 2005; McWey et al. 2015). Particularly due to variations in the length of time youth lived with their current caregivers (and, therefore, caregivers who may not have known the youth for very long may not provide as accurate an assessment as the youth themselves), we opted to use youth rather than caregiver report. However, future research can examine if the same pattern of results persists when using caregiver report. Despite these issues, the results of this study indicated key linkages between trauma, thought problems, and aggression over time specifically for youth in foster care. Approaching the mental health treatment of youth in foster care from developmental trauma perspective (van der Kolk 2005) may be a key to helping improve the poor prognosis of youth with high levels of aggression.

Future research may be needed to expand on these limitations. For instance, the dataset only accounted for biological sex but not gender identity, while the terms sex and gender are often used interchangeably, sex refers to the biological distinction between males and females, whereas gender refers to the much more complex cultural understanding. Therefore, future research may help expand on these findings by understanding both sex and gender identity as it relates to the interrelationships between trauma, thought problems, and aggression. The current study may also be expanded on by utilizing a broader understanding of traumatic experiences, considering adverse childhood experiences (ACEs), and those not included in the traditional list of ACEs, as a means of translating research findings into effective interventions and policies (Weems et al. 2021). Moreover, only trauma scores from wave 1 were utilized in this study and including trauma reports from each wave may also bolster future research. In general, future research also may benefit from including more waves of data to expand the analyses that can be done, including higher order polynomial models such as quadratic or cubic models. Additionally, the analyses did not consider the nesting of participants within their respective regions and must be considered in future studies Finally, although this paper was written during the global pandemic of COVID-19, NSCAW II data were collected prior to COVID-19. Therefore, future research may benefit from understanding the interrelationships of these variables with consideration of how the pandemic may have a unique effect on thought problems and aggression of youth in foster care.

\section{Conclusions}

The aim of this study was to determine the longitudinal trajectories of thought problems and aggression for youth in foster care. Although some espouse that thought problems may play a central role in aggressive behaviors (Fives et al. 2011, Smeijers et al. 2018), there is limited research testing this hypothesis with youth in foster care. This is important because youth in foster care are at risk for aggressive behavior problems (De Robertis and Litrownik 
2004; Heflinger et al. 2000) and youth who exhibit high levels of aggression tend to have poorer treatment outcomes (Cantos and Gries 2010; Fives et al. 2011). Given the known mental health needs of many youths in foster care, it is important to better understand factors associated with aggression. Results indicated significant associations between trauma, thought problems, and aggression over time. Strengths of this study included the use of nationally representative data of youth in foster care and longitudinal modeling. Findings can be used to inform mental health interventions for adolescents in foster care who struggle with aggressive behaviors.

\section{References}

Achenbach, T. M. (1991). Manual for the youth self-report and 1991 profile. Burlington: Department of Psychiatry, University of Vermont

Achenbach, T. M., \& Rescorla, L. A. (2001). Manual for the ASEBA school-age forms \& profiles. Burlington: University of Vermont, Research Center for Children, Youth, \& Families

Ambrose, T. K., \& Mayne, T. J. (1999). Research review on anger in psychotherapy. Clinical Psychology, 55, 353?363. https://doi.org/10.1002/(SICI)1097-4679(199903)55:3<353::AID-JCLP7>3.0.CO;2-B

Barriga, A. Q., Landau, J. R., Stinson, B. L., Liau, II., A. K., \& Gibbs, J. C. (2000). Cognitive distortion and problem behaviors in adolescents. Criminal Justice and Behavior, 27, 36-56. https://doi. org/10.1177/0093854800027001003

Berkowitz, L. (2012). A different view of anger: The cognitive-neoassociation conception of the regulation of the relation of anger to aggression. Aggressive Behavior, 38, 322-333.

Bradshaw, C. P., Goldweber, A., \& Garbarino, J. (2013). Linking social-environmental risk factors with aggression in suburban adolescents: The role of social-cognitive mediators. Psychology in the Schools, 50(5), 433-450. https://doi.org/10.1002/pits.21690

Briere, J. (1996). Trauma symptom checklist for children: professional manual. Odessa: Psychological Assessment Resources

Cantos, A., \& Gries, L. (2010). Therapy outcome with children in foster care: A longitudinal study. Child \& Adolescent Social Work Journal, 27, 133-149. https://doi.org/10.1007/s10560-010-0198-5

Chaplin, T. M., Cole, P. M., \& Zahn-Waxler, C. (2005). Parental socialization of emotional expression: gender differences and relations to child adjustment. American Psychological Association, 5, 80-88. https:// doi.org/10.1037/1528-3542.5.1.80

Christiansen, D. M., \& Hansen, M. (2015). Accounting for sex differences in PTSD: A multi-variable mediation model. European Journal of Psychotraumatology, 6(1), 26068. https://doi.org/10.3402/ejpt. v6.26068

Cicchetti, D., \& Rogosch, F. A. (2002). A devel- opmental psychopathology perspective on ado- lescence. Journal of Consulting and Clinical Psychology, 70, 6-20

Clausen, J. M., Landsverk, J., Ganger, W., Chadwick, D., \& Litrownik, A. (1998). Mental health problems of children in foster care. Journal of Child \& Family Studies, 7, 283-296. https://doi.org/10.102 3/A:1022989411119

Coie, J. D., \& Dodge, K. A. (1998). Aggression and antisocial behavior. In Damon, W., \& Eisenberg, N. (Eds.), Handbook of child psychology: Vol. 3, Social emotional, and personality development (pp. 779862). New York: Wiley

den Dunnen, W., Pierre, J., Stewart, S. L., Johnson, A., Cook, S., \& Leschied, A. W. (2012). Predicting residential treatment outcomes for emotionally and behaviorally disordered youth: the role of pre- treatment factors. Residential Treatment for Children \& Youth, 29, 13-31. https://doi.org/10.1080/08865 $71 X .2012 .642268$

De Los Reyes, A., \& Kazdin, A. E. (2005). Informant discrepancies in the assessment of childhood psychopathology: A critical review, theoretical framework, and recommendations for further study. Psychological Bulletin, 131, 483-509

De Robertis, M. T., \& Litrownik, A. J. (2004). The experience of foster care: Relationship between foster parent disciplinary approaches and aggression in a sample of young foster children. Child Maltreatment, 9 , 92-102. https://doi.org/10.1177/1077559503260402

de Vries, S. L., Hoeve, M., Stams, G. J., \& Asscher, J. J. (2016). Adolescent-parent attachment and externalizing behavior: The mediating role of individual and social factors. Journal of Abnormal Child Psychology, 2, 283-294. doi: https://doi.org/10.1007/s10802-015-9999-5 
Dowd, K., Dolan, M., Wallin, J., Miller, K. A., Biemer, P., Aragon-Logan, E., ... \& Smith, K. (2010). National Survey of Child and Adolescent Well-Being II: Data file user's manual restricted release version. Ithaca, NY: National Data Archive on Child Abuse and Neglect

Farley, T. M., McWey, L. M., \& Lederman, T. (2020). Trauma and violence as predictors of internalizing and externalizing symptoms of youth in residential child welfare placements. Journal of Family Violence, 36, 249-258. doi: https://doi.org/10.1007/s10896-020-00140-w

Fives, C. J., Kong, G., Fuller, J. R., \& DiGiuseppe, R. (2011). Anger, aggression, and irrational beliefs in adolescents. Cognitive Therapy and Research, 35, 199-208. doi: https://doi.org/10.1007/s10608-009-9293-3

Frensch, K. M., \& Cameron, G. (2002). Treatment of choice or last resort? A review of residential mental health placements for children and youth. Child \& Youth Care Forum, 31, 307-339. https://doi.org/10 .1023/A:1016826627406

Garcia, A. R., Aisenberg, E., \& Harachi, T. (2012). Pathways to service inequalities among Latinos in the child welfare system. Children and Youth Services Review, 34, 1060-1071. https://doi.org/10.1016/j. childyouth.2012.02.011

Garcia, A. R., Greeson, J. K. P., Kim, M., Thompson, A., \& DeNard, C. (2015). From placement to prison: do mental health services disrupt the delinquency pipeline among Latino, African American and Caucasian youth in the child welfare system? Journal of Adolescence, 45, 263-273. https://doi.org/10.1016/j. adolescence.2015.10.008

Glancy, G., \& Saini, M. A. (2005). An evidenced-based review of psychological treatments of anger and aggression. Brief Treatment and Crisis Intervention, 5(2), 229-248. https://doi.org/10.1093/ brief-treatment/mhi013

Goldberg, L. R., \& Freyd, J. J. (2006). Self-reports of potentially traumatic experiences in an adult community sample: Gender differences and test-retest stabilities of the items in a brief betrayal-trauma survey. Journal of Trauma and Dissociation, 7, 39-63. doi: https://doi.org/10.1300/J229v07n03_04

Hamama, L., \& Arazi, Y. (2012). Aggressive behaviour in at-risk children: contribution of subjective well-being and family cohesion. Child \& Family Social Work, 17, 284-295. https://doi. org/10.1111/j.1365-2206.2011.00779.x

Heflinger, C. A., Simpkins, C. G., \& Combs-Orme, T. (2000). Using the CBCL to determine the clinical status of children in state custody. Children and Youth Services Review, 22, 55-63. https://doi.org/10.1016/ S0190-7409(99)00073-0

Henggeler, S. W., \& Sheidow, A. J. (2003). Conduct disorder and delinquency. Journal of Marital and Family Therapy, 29, 505-522. https://doi.org/10.1111/j.17520606.2003.tb01692.x

Henning, K. N. (2012). Criminalizing Normal Adolescent Behavior in Communities of Color: The Role of Prosecutors in Juvenile Justice Reform. SSRN Electronic Journal. doi: https://doi.org/10.2139/ Ssrn. 2128857

Herz, D. C., \& Dierkhising, C. B. (2019). OJJDP dual system youth design study: Summary of findings and recommendations for pursuing a national estimate of dual system youth. https://www.ncjrs.gov/pdffiles1/ojjdp/grants/252717.pdf

Ho, B. P. V., Carter, M. C., \& Stephenson, J. (2010). Anger management using a cognitive-behavioural approach for children with special education needs: a literature review and meta analysis. International Journal of Disability, Development, and Education, 57, 245-265. https://doi.org/10.1080/10349 12X.2010.501169

Hockenberry, S., \& Puzzanchera, C. (2019). Juvenile Court Statistics 2017. Pittsburgh, Pa: National Center for Juvenile Justice: Report

Horwitz, S. M., Hurlburt, M. S., Goldhaber-Fiebert, J. D., Heneghan, A. M., Zhang, J., Rolls-Reutz, J., ... \& Stein, R. E. (2012). Mental health service use by children investigated by child welfare agencies. Pediatrics, 130, 861-869. https://doi.org/10.1542/peds.2012-1330

Johnson, A. L., Nelson, W. M., III, Ghee, A. C., \& Deardorff, P. A. (2013). Types of aggression among incarcerated juveniles: The roles of gender and offense type. Journal of Aggression, Maltreatment \& Trauma, 22(3), 300-315. https://doi.org/10.1080/10926771.2013.743943

Kanne, S. M., \& Mazurek, M. O. (2010). Aggression in Children and Adolescents with ASD: Prevalence and Risk Factors. Journal of Autism and Developmental Disorders, 41(7), 926-937. doi: https://doi. org/10.1007/s10803-010-1118-4

Keller, T. E., Wetherbee, K., LeProhn, N. S., Payne, V., Sim, K., \& Lamont, E. R. (2001). Competencies and problem behaviors of children in family foster care: Variations by kinship placement status and race. Children and Youth Services Review, 23, 915-940. doi: https://doi.org/10.1016/S0190-7409(01)00175-X

Kisiel, C. L., Fehrenbach, T., Torgersen, E., Stolch, B., McClelland, G., Griffin, G., \& Burkman, K. (2014). Constellations of interpersonal trauma and symptoms in child welfare: Implications for a developmental trauma framework. Journal of Family Violence, 29, 1-14. doi: https://doi.org/10.1007/ s10896-013-9559-0 
Kolko, D. J., Hurlburt, M. S., Zhang, J., Barth, R. P., Leslie, L. K., \& Burns, B. J. (2010). Posttraumatic stress symptoms in children and adolescents referred for child welfare investigation. Child Maltreatment, 15, 48-63. https://doi.org/10.1177/1077559509337892

Kools, S. M. (1997). Adolescent identity development in foster care. Family Relations, 46, 263-271. https:// doi-org.proxy.lib.fsu.edu/10.2307/585124

Korbin, J., Celeste, G., \& Miller-Fellows, S. (2015). Transitions to adulthood for foster care and justice system-involved youth. https:/www.neighborhoodindicators.org/sites/default/files/publications/Cleveland\%20Policy\%20Brief\%20Short\%20Version.pdf

Knoverek, A. M., Briggs, E. C., Underwood, L. A., \& Hartman, R. L. (2013). Clinical considerations for the treatment of latency age children in residential care. Journal of Family Violence, 28, 653-663. https:// doi.org/10.1007/s10896-013-9536-7

Ledermann, T., \& Kenny, D. A. (2017). Analyzing dyadic data with multilevel modeling versus structural equation modeling: A tale of two methods. Journal of Family Psychology, 31(4), 442-452. https://doi. org $/ 10.1037 /$ fam0000290

Little, T. D., Brauner, J., Jones, S. M., Nock, M. K., \& Hawley, P. H. (2003). Rethinking aggression: A typological examination of the functions of aggression. Merrill-Palmer Quarterly, 49(3), 343. https://www. jstor.org/stable/i23096053

Marinkovic, J. A., \& Backovic, D. (2007). Relationship between type of placement and competencies and problem behavior of adolescents in long-term foster care. Children and Youth Services Review, 29, 216-225. https://doi-org.proxy.lib.fsu.edu/10.1016/j.childyouth.2006.08.004

McMillen, J. C., Zima, B. T., Scott, L. D., Auslander, W. F., Munson, M. R., Ollie, M. T., \& Spitznagel, E. L. (2005). Prevalence of psychiatric disorders among older youths in the foster care system. Journal of the American Academy of Child \& Adolescent Psychiatry, 44(1), 88-95. https://doi.org/10.1097/01. chi.0000145806.24274.d2

McWey, L. M., Cui, M., \& Holtrop, K. (2015). Caregiver-adolescent dyadic disagreement and problem behaviors of adolescents in the child welfare system. Journal of Research on Adolescence, 25, 44-50. doi: https://doi.org/10.1111/jora.12105

McWey, L. M., Cui, M., \& Pazdera, A. L. (2010). Changes in externalizing and internalizing problems of adolescents in foster care. Journal of Marriage and Family, 72, 1128-1140. doi: https://doi. org/10.1111/j.1741-3737.2010.00754.x

Mooney, J. L., \& Daffern, M. (2011). Institutional aggression as a predictor of violent recidivism: Implications for parole decision making. International Journal of Forensic Mental Health, 10, 52-63. doi: https://doi.org/10.1080/14999013.2010.550984

National Data Archive on Child Abuse and Neglect (NDACAN). https://www.ndacan.acf.hhs.gov/

Nguyen, L., Huang, L. N., Arganza, G. F., \& Liao, Q. (2007). The influ- ence of race and ethnicity on psychiatric diagnoses and clinical characteristics of children and adolescents in children's services. Cultural Diversity and Ethnic Minority Psychology, 13, 18-25. https://doi.org/10.1037/1099-9809.13.1.18

Perry, K., \& Price, J. M. (2017). The role of placement history and current family environment in children's aggression in foster care. Journal of Child \& Family Studies, 26(4), 1135-1150. https://doi.org/10.1007/ s10826-016-0642-z

Scott, B. G., Lapré, G. E., Marsee, M. A., \& Weems, C. F. (2013). Aggressive behavior and its associations with posttraumatic stress and academic achievement following a natural disaster. Journal of Clinical Child \& Adolescent Psychology, 43(1), 43-50. doi: https://doi.org/10.1080/15374416.2013.807733

Substance Abuse and Mental Health Services Administration. (2014). SAMHSA's Concept of trauma and guidance for a trauma-informed approach. https://ncsacw.samhsa.gov/userfiles/files/SAMHSA Trauma.pdf

Substance Abuse and Mental Health Services Administration. (2015). Trauma Informed Approach and Trauma Specific Interventions. https://www.samhsa.gov/nctic/trauam-interventions

Sevin Goldstein, N. E., Dovidio, A., Kalbeitzer, R., Weil, J., \& Strachan, M. (2007). Anger management for female juvenile offenders: Results of a pilot study. Journal of Forensic Psychology Practice, 7, 1-28. doi: https://doi.org/10.1300/J158v07n02_01

Sharp, S. F., Brewster, D., \& RedHawk Love, S. (2005). Disentangling strain, personal attributed, affective response and deviance: A gendered analysis. Deviant Behavior, 26(2), 133-157. https://doi. org/10.1080/01639620590522028

Smeijers, D., Brazil, I. A., Bulten, E. B. H., \& Verkes, R. J. (2018). Retrospective parental rejection is associated with aggressive behavior as well as cognitive distortions in forensic psychiatric outpatients. Psychology of Violence, 8(4), 495-504. https://doi.org/10.1037/vio0000134

Spindler, H., Elklit, A., \& Christiansen, D. M. (2010). Risk factors for posttraumatic stress disorder following an industrial disaster in a residential area: A note on the origin of observed gender differences. Gender Medicine, 7, 156-165. doi: https://doi.org/10.1016/j.genm.2010.04.001 
Strijker, J., Zandberg, T., \& Van der Meulen, B. F. (2005). Typologies and outcomes for foster children. Child \& Youth Care Forum, 34, 43-55. https://doi.org/10.1007/s10566-004-0881-9

Tarren-Sweeney, M. (2008). Retrospective and concurrent predictors of the mental health of children in care. Children and Youth Services Review, 30, 1-25. doi: https://doi.org/10.1016/j.childyouth.2007.05.014

Thurber, S., \& Sheehan, W. P. (2012). Note on truncated T scores in discrepancy studies with the Child Behavior Checklist and Youth Self Report. Archives of Assessment Psychology, 2, 73-80

Tolin, D. F., \& Foa, E. B. (2008). Sex differences in trauma and posttraumatic stress disorder: A quantitative review of 25 years of research. Psychological Trauma: Theory, Research, Practice and Policy, 37-85. doi: https://doi.org/10.1037/1942-9681.S.1.37

Tolan, P. H., \& Henry, D. (1996). Patterns of psychopathology among urban poor children: Comorbidity and aggression effects. Journal of Consulting and Clinical Psychology, 64(5), 1094-1099. doi: https://doi. org/10.1037/0022-006x.64.5.1094

Tonnaer, F., Cima, M., \& Arntz, A. (2019). Explosive matters: Does venting anger reduce or increase aggression? Differences in anger venting effects in violent offenders. Journal of Aggression, Maltreatment, \& Trauma. doi: https://doi.org/10.1080/10926771.2019.1575303

Tremblay, R. E., Hartup, W. W., \& Archer, J. (2005). Developmental origins of aggression. Guilford

U.S. Department of Health and Human Services. (2015). Adoption \& foster care statistics. Retrieved from http://www.acf.hhs.gov/programs/cb/research-data-technology/statistics-research/afcars

Valois, R. F., MacDonald, J. M., Bretous, L., Fischer, M. A., \& Drane, J. W. (2002). Risk factors and behaviors associated with adolescent violence and aggression. Proceedings of the 2nd Scientific Meeting of the American Academy of Health Behavior, March 24-27, 2002, Napa Valley, CA. American Journal of Health Behavior, 26(6), 454-464. https://doi-org.proxy.lib.fsu.edu/10.5993/ajhb.26.6.6

van der Kolk, B. A. (2005). Developmental trauma disorder: Toward a rational diagnosis for children with complex trauma histories. Psychiatric Annals, 35, 401-408. https://doi.org/10.3928/00485713-20050501-06

van der Kolk, B. A., Pynoos, R., Cicchetti, D., Cloitre, M., D’Andrea, W., Ford, J., ... \& Teicher, M. (2009). Proposal to include a Developmental Trauma Disorder diagnosis for children and ado-lescents in $D S M-V$ [Unpublished manuscript]. Retrieved from http://www.traumacenter.org/announcements/DTD papers_Oct_09.pdf

Weems, C. F., Russell, J. D., Herringa, R. J., \& Carrion, V. G. (2021). Translating the neuroscience of adverse childhood experiences to inform policy and foster population-level resilience. American Psychologist, 76(2), 188-202. doi: https://doi.org/10.1037/amp0000780

Weems, C. F., McCurdy, B. H., \& Scozzafava, M. D. (in press). Toward a developmental model of continuity and change in PTSD symptoms following exposure to traumatic and adverse experiences. Journal of Child and Adolescent Trauma.https://doi.org/10.1007/s40653-021-00398-2

Publisher's Note Springer Nature remains neutral with regard to jurisdictional claims in published maps and institutional affiliations. 